\title{
RELATIONSHIP AMONG PREPARATION, STRUCTURE AND SUPERCONDUCTIVITY IN Tl-Ca-Ba-Cu-O COMPOUNDS
}

\author{
I. KIRSCHNER \\ Department for Low Temperature Physics, Eötvös University, Budapest, Hungary \\ Microelectronics Laboratory, University of Oulu, Oulu, Finland \\ S. LEPPÄVUORI \\ Microelectronics Laboratory, University of Oulu, Oulu, Finland \\ A. UUSIMÄKI \\ Microelectronics Laboratory, University of Oulu, Oulu, Finland \\ (Received November 15, 1992; in final form December 16, 1992)
}

\begin{abstract}
Analysis of a comprehensive set of experimental results has proven the substantial effect of the precise preparation conditions upon the structure and superconducting parameters of $\mathrm{Tl}-\mathrm{Ca}-\mathrm{Ba}-\mathrm{Cu}-\mathrm{O}$ samples. The techniques required for the preparation of specimens of single phase and long-term stability, together with methods for improvement of the characteristic parameters have been determined. Comparing results derived from samples prepared by different methods has allowed the quantitative differences of the characteristic parameters to be evaluated.
\end{abstract}

\section{INTRODUCTION}

The chemical quality of the starting materials, their mixture, and subsequent heat treatment determine the microstructure that in turn controls the superconducting features of different samples.

The discovery of Sheng and Hermann ${ }^{1}$ provided a possibility for developing a new family of high- $\mathrm{T}_{\mathrm{c}}$ superconductors, namely $\mathrm{Tl}-\mathrm{Ca}-\mathrm{Ba}-\mathrm{Cu}-\mathrm{O}$. With the help of these compounds, higher critical temperatures can be reached than is possible with the $\mathrm{La}-\mathrm{Ba}-\mathrm{Cu}-\mathrm{O}, \mathrm{Y}-\mathrm{Ba}-\mathrm{Cu}-\mathrm{O}$ and $\mathrm{Bi}(\mathrm{Pb})-\mathrm{Sr}-\mathrm{Ca}-\mathrm{Cu}-\mathrm{O}$ oxides.

The experiments that were previously carried out on the Tl-based materials showed that the properties of the specimens were influenced very strongly by the fine details of the preparation process ${ }^{2.3 .4}$. The different methods of preparation caused different microscopic and macroscopic structures as well as deviations in the local and global properties of specimens.

\section{TYPES OF INVESTIGATION}

Different structural and physical features of samples can be detected by a wide range of investigating procedures, namely TG, DTA, X-ray, SEM, TEM (SAED 
and HRTEM), EDS, microprobe, STM, resistivity measurement, d.c. and a.c. susceptibility, SQUID, ESR, NMR, hysteresis, and Mössbauer-spectroscopy. These provide useful information on the character of the superconducting transition, superconducting material content, structural and temporal stability, phononelectron coupling, phases and impurities, site and change of ions, type of charge carriers, critical parameters (temperatures, magnetic fields and currents), coherence length, penetration depth and GL-parameter, gap, unit cell parameters and the characteristics of surfaces and grains.

\section{STRUCTURE}

Numerous scientific investigations have been devoted to clarifying the structure of samples and the composition of superconducting phases of Tl-based materials using $\mathrm{X}$-ray ${ }^{5,6}$, neutron diffraction ${ }^{7}$, microprobe, and transmission electron microscopy ${ }^{8}$ methods. During these investigations the number, the type and the quantity of superconducting phases were determined.

Six separate superconducting Tl-Ca-Ba-Cu-O phases can be distinguished ${ }^{9}$. The type and lattice constants of the unit cells, and the critical temperature are as follows:

$\mathrm{Tl}_{1} \mathrm{Ca}_{1} \mathrm{Ba}_{2} \mathrm{Cu}_{2} \mathrm{O}_{7}$, prim. tetragonal, $\mathrm{a}=3.84 \AA, \mathrm{c}=12.63 \AA, \mathrm{T}_{\mathrm{c}}=65-85 \mathrm{~K}$, $(1,1,2,2)$

$\mathrm{Tl}_{1} \mathrm{Ca}_{2} \mathrm{Ba}_{2} \mathrm{Cu}_{3} \mathrm{O}_{9}$, prim. tetragonal, $\mathrm{a}=3.84 \AA$, $\mathrm{c}=15.87 \AA, \mathrm{T}_{\mathrm{c}}=100-110 \mathrm{~K}$, $(1,2,2,3)$

$\mathrm{Tl}_{1} \mathrm{Ca}_{3} \mathrm{Ba}_{2} \mathrm{Cu}_{4} \mathrm{O}_{11}$, prim. tetragonal, $\mathrm{a}=3.85 \AA, \mathrm{c}=19.12 \AA, \mathrm{T}_{\mathrm{c}}=110-120 \mathrm{~K}$, $(1,3,2,4)$

$\mathrm{Tl}_{2} \mathrm{Ca}_{0} \mathrm{Ba}_{2} \mathrm{Cu}_{1} \mathrm{O}_{6}$, b.c. tetragonal, $\mathrm{a}=3.85 \AA, \mathrm{c}=23.23 \AA, \mathrm{T}_{\mathrm{c}}=20-80 \mathrm{~K}$, $(2,0,2,1)$

$\mathrm{Tl}_{2} \mathrm{Ca}_{1} \mathrm{Ba}_{2} \mathrm{Cu}_{2} \mathrm{O}_{8}$, b.c. tetragonal, $\mathrm{a}=3.86 \AA, \mathrm{c}=29.32 \AA, \mathrm{T}_{\mathrm{c}}=95-108 \mathrm{~K}$, $(2,1,2,2)$

$\mathrm{Tl}_{2} \mathrm{Ca}_{2} \mathrm{Ba}_{2} \mathrm{Cu}_{3} \mathrm{O}_{10}$, b.c. tetragonal, $\mathrm{a}=3.86 \AA, \mathrm{c}=35.88 \AA, \mathrm{T}_{\mathrm{c}}=115-125 \mathrm{~K}$, $(2,2,2,3)$.

The difference in $T_{c}$ of a given phase is caused by lattice defects, stacking faults, and strange ions existing in the perovskite and rock salt units of the structure. They affect both the superconducting volume fraction and critical parameters at the same time.

A direct correlation between the number of $\mathrm{Cu}-\mathrm{O}$ planes and the critical temperature was also found, in that the increasing number of $\mathrm{Cu}-\mathrm{O}$ layers resulted in an increasing $\mathrm{T}_{\mathrm{c}}$. Accordingly, the unit cells having one, two or three $\mathrm{Cu}-\mathrm{O}$ planes are characterized by $T_{c}$ of about $80 \mathrm{~K}, 105 \mathrm{~K}$ and $125 \mathrm{~K}$, respectively. 


\section{EFFECT OF PREPARATION METHODS}

Because of the ionic radii of the constituent elements, the thermal activation for the dissociation of the starting materials, the substitution of $\mathrm{La}, \mathrm{Y}, \mathrm{Bi}$ and $\mathrm{Tl}$ with other atoms, the ratio of the cations to the $\mathrm{Cu}$, the chemical potential, and the bond strength for the new compounds all vary from system to system. To forecast the exact number, composition, and share-rate of the superconducting phases in the final products is very difficult. It is also obstructed by the appearance of nonstoichiometric modifications. As a result, the development of the desired mixture of phases or single-phase material can be reached only on the basis of the experience obtained during the series of experiments.

(1). As an example of the effect of different starting compounds on the structure and superconductivity of specimens, an investigation concerning this question ${ }^{10}$ can be cited. Three groups of samples were prepared from starting compounds as: $\mathrm{TlNO}_{3}, \mathrm{CaO}, \mathrm{BaO}, \mathrm{CuO}(\mathrm{A}) ; \mathrm{TlNO}_{3}, \mathrm{CaO},\left(\mathrm{BaNO}_{3}\right)_{2}, \mathrm{CuO}(\mathrm{B})$; and $\mathrm{TlNO}_{3}$, $\mathrm{CaO},\left(\mathrm{BaNO}_{3}\right)_{2}, \mathrm{CuO}$ in pure $\mathrm{O}_{2}$ atmosphere $(\mathrm{C})$. The heat treatment consisted mainly as follows: The mixed and ground starting compounds were pre-heated at $400^{\circ} \mathrm{C}$ in air for $0.5 \mathrm{~h}$, then cooled to room temperature over $2 \mathrm{~h}$. The first solid state reaction occurred at $800^{\circ} \mathrm{C}$ for $10 \mathrm{~min}$, followed by a slow cooling of $7^{\circ} \mathrm{C} /$ min. After grinding and mixing, the product was pressed into blocks at a pressure of $5 \mathrm{MPa}$, sintered at $940^{\circ} \mathrm{C}$, then cooled to $800^{\circ} \mathrm{C}$ in $5 \mathrm{~min}$ and to then room temperature at a rate of $150^{\circ} \mathrm{C} / \mathrm{min}$. In the case of samples $\mathrm{C}$, purified $\mathrm{O}_{2}$ was added during the annealing process.

The SEM photographs (JEOL G-35) clearly show a difference in the morphology of the microstructure of samples, which is the consequence of different starting compounds employed. As is seen in Fig. 1, specimens A have round microcrystals and homogeneous structure. In contrast, samples B contain some glassy areas between the crystallites of different shapes. This structural character may be associated with the starting compound of $\mathrm{Ba}\left(\mathrm{NO}_{3}\right)_{2}$ having a low melting point of $580^{\circ} \mathrm{C}$ and high reactivity during heat treatment. Finally, the morphology of the microcrystalline structure of specimens $C$ hints at the presence of copper oxides.

The role of the different starting compounds can also be demonstrated by the $\mathrm{X}$-ray diffractograms (Philips $\mathrm{PW}-1360$, using $\mathrm{CuK} \alpha$ radiation), as shown in Fig. 2. Samples A were constituted mostly from the $(2,1,2,2)$ phase having a medium degree of crystallinity. The first high intensity line was found at $2 \theta=6.09^{\circ}$, detecting a slightly contracted tetragonal unit cell with a lattice constant of $c=29.03 \AA$. The peak at $2 \theta=7.60^{\circ}$ indicates the presence of the $(2,0,2,1)$ phase in the quantity of $1-2 \%$. A very small amount of $\mathrm{BaCuO}_{2}$ is present as well. These facts demonstrate the quasi-single phase superconducting nature of these samples. The diffraction pattern of specimens B shows a weakly crystallized structure. The glassy character is caused by the low melting point of $\mathrm{Ba}\left(\mathrm{NO}_{3}\right)_{2}$, because it decomposes to $\mathrm{BaO}$ (and in situ $\mathrm{Ba}_{2} \mathrm{O}_{2}$ ) between the temperatures of $650^{\circ} \mathrm{C}$ and $775^{\circ} \mathrm{C}$, the presence of which leads to a glassy structure. Among the superconducting phases, $(2,1,2,2)$ is the most prevalent $\sim 80 \%$ and $(1,2,2,3)$ and $(2,2,2,3)$ exist in $\sim 20 \%$. They constitute the whole material of samples in $80-85 \%$ and the residual part of it consists of mainly $\mathrm{BaCuO}_{2}$. The diffraction picture of samples $\mathrm{C}$ represents 

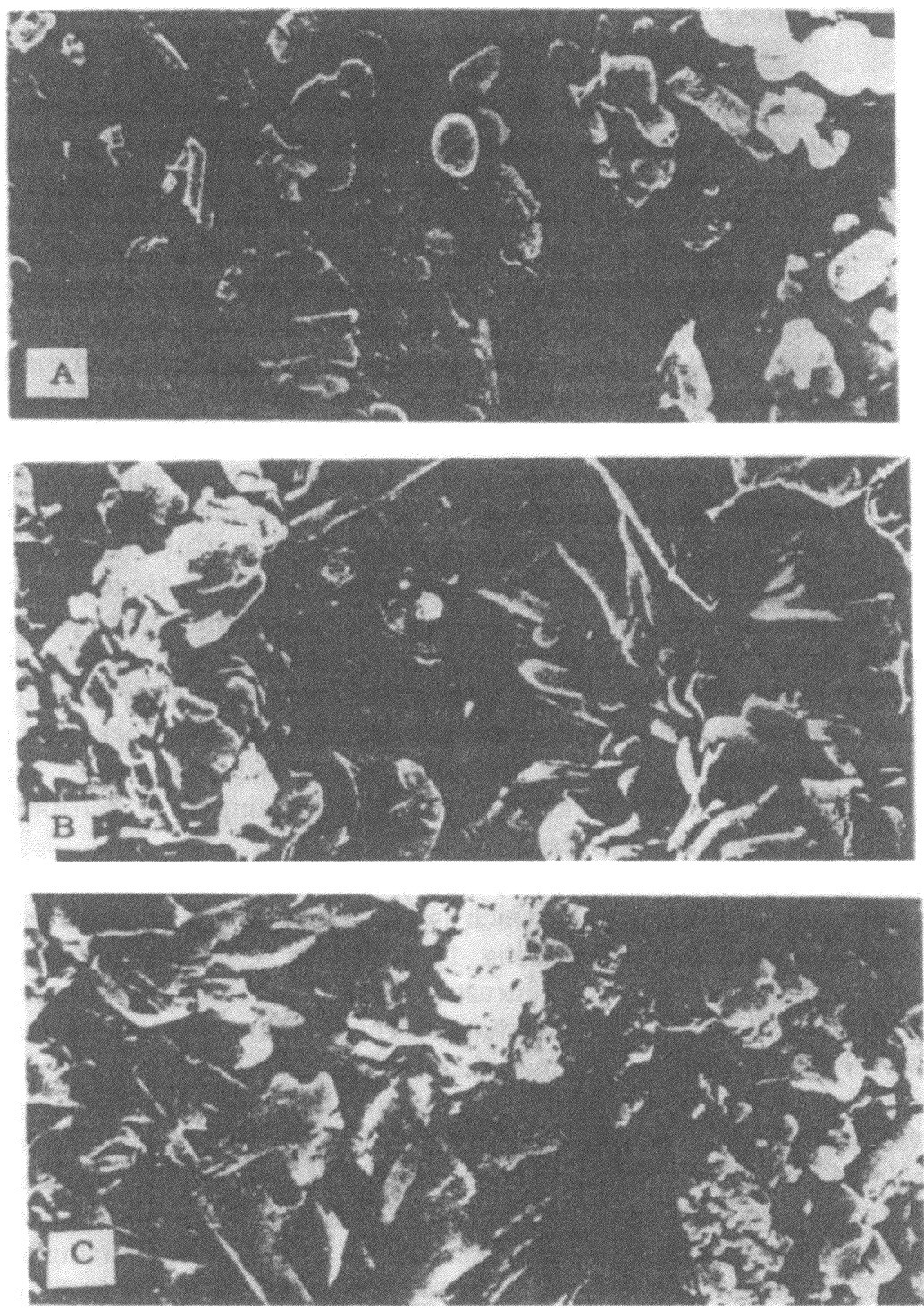

FIGURE 1 SEM micrographs of samples prepared from different groups of starting materials

again the $(2,1,2,2)$ as the main phase, but leads to the conclusion of the presence of $\mathrm{CuO}$ and $\mathrm{Cu}_{2} \mathrm{O}$, indicated by the lines at $2 \theta=35.49^{\circ}, 35.57^{\circ}, 38.77^{\circ}$, and at $2 \theta$ $=36.50^{\circ}$ and $42.34^{\circ}$, respectively.

The use of different preparation materials also affects the electrical and magnetic behavior of the specimens.

All of the samples have metallic characteristics over the complete temperature range under investigation, low normal specific resistivity and onset- and critical 


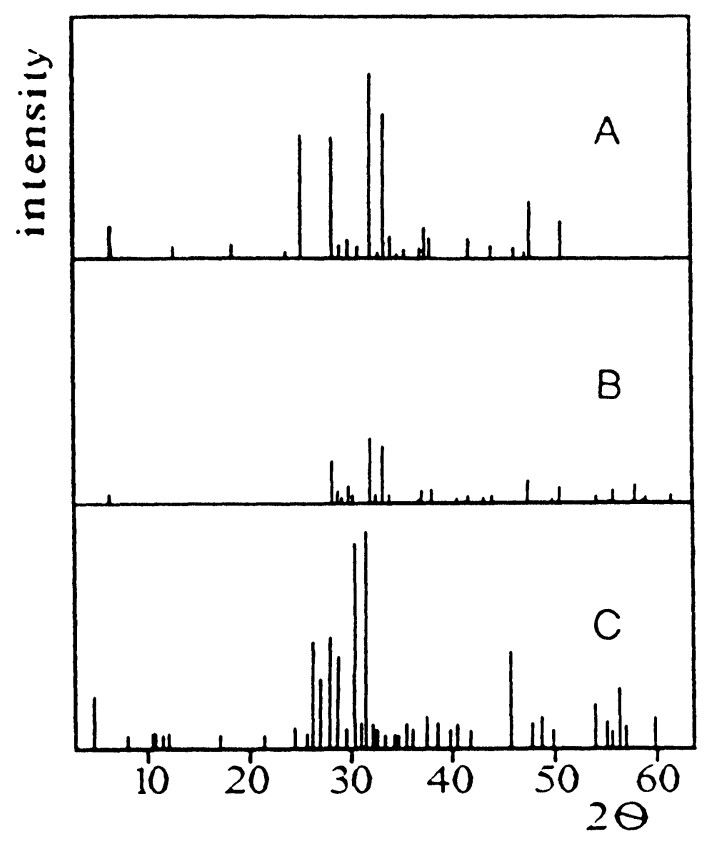

FIGURE 2 Different X-ray diffraction patterns reflecting the difference in preparation

temperatures $T_{0}$ and $T_{c}$ above $100 \mathrm{~K}$ (Fig. 3). However, the values of these parameters vary (see Table 1 ) depending on the groups of initial materials.

The temperature dependence of d.c. magnetization measured by a SQUIDmagnetometer (Biomagnetic Technologies) reflects the quality and phase structure of the specimens (Fig. 4). The shape of the curves of d.c. susceptibility vs temperature suggests a nearly single-phase superconductivity of $(2,1,2,2)$ except for

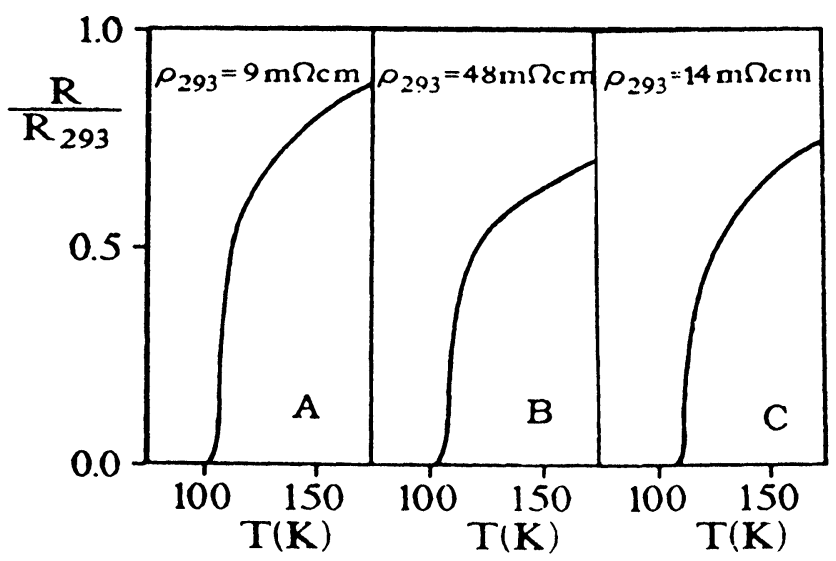

FIGURE 3 The deviating resistivity curves according to the unlike starting compounds 
TABLE 1

Onset- and critical temperature of diamagnetic transition for samples of different starting materials

\begin{tabular}{llll}
\hline Samples & $\mathrm{T}_{0}(\mathrm{~K})$ & $\mathrm{T}_{\mathrm{c}}(\mathrm{K})$ & $\mathrm{T}_{\mathrm{d}}(\mathrm{K})$ \\
\hline A & 116 & 101 & 103 \\
B & 117 & 105 & 104 \\
C & 121 & 111 & 109 \\
\hline
\end{tabular}

samples $\mathrm{A}$, where the $(2,0,2,1)$ content deforms the characteristic. Comparing Figs. 3 and 4 , the coincidence of the appearance of superconductivity from the electrical and magnetic points of view seems to be obvious.

Vibrating sample magnetometers (Oxford Instruments) or SQUID magnetometers (as mentioned above) are very suitable for determining magnetic hysteresis phenomena in high- $\mathrm{T}_{\mathrm{c}}$ superconductors and their dependence on the preparation components, namely on the starting materials. Important physical parameters can be calculated from the hysteresis loops, e.g., the lower critical magnetic field and the intergrain and intragrain critical currents ${ }^{11}$. The magnetization (M)-magnetic field $(\mathrm{H})$ curves presented in Fig. 5 were taken at $77 \mathrm{~K}$.

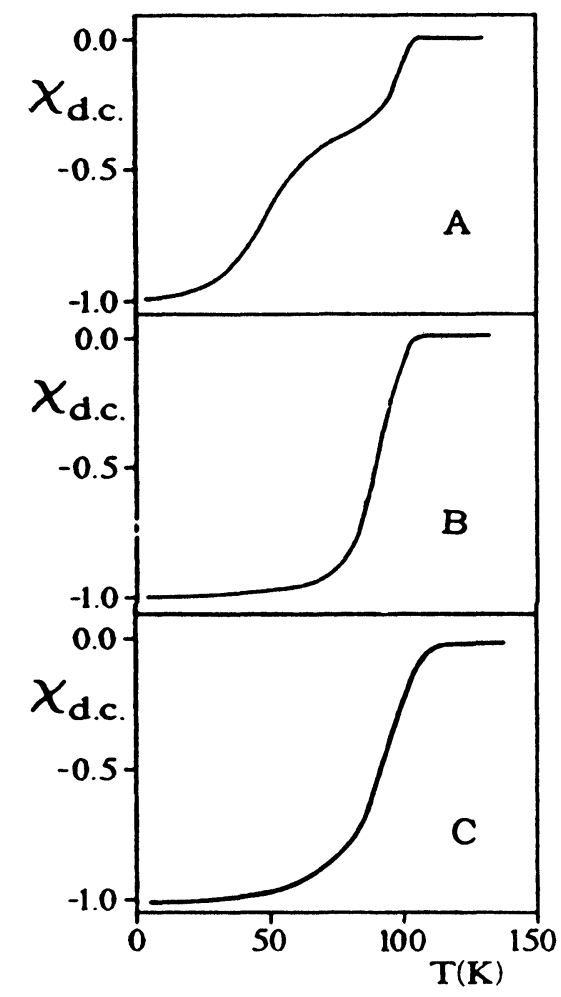

FIGURE 4 D.c. susceptibility vs temperature for different specimens 


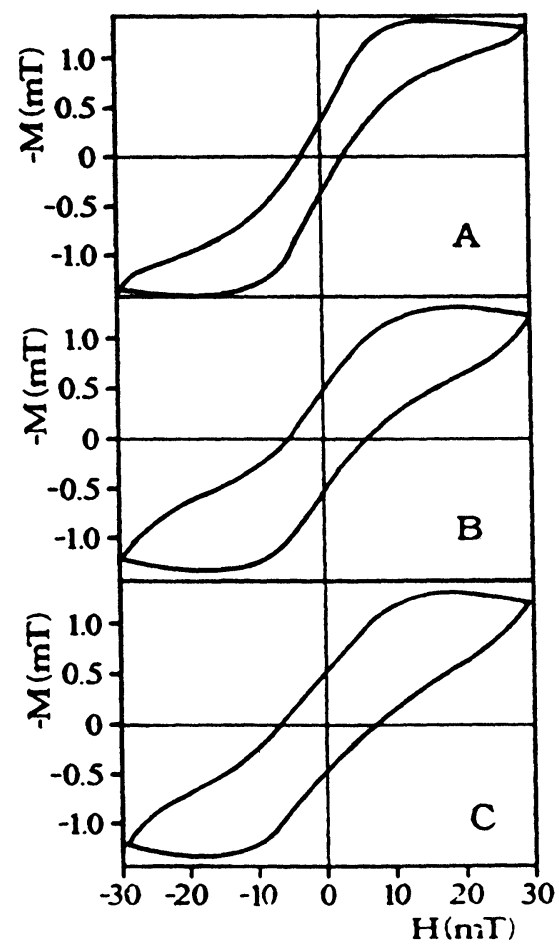

FIGURE 5 Magnetic hysteresis at $77 \mathrm{~K}$

Three methods can be applied for the determination of $\mathrm{H}_{\mathrm{cl}}$, namely to select the maximum point of the curves, to select the intersection of the increasing and decreasing branches, or to select the point where the deviation from linearity begins. These methods lead to the possible minimum values of the lower critical field extrapolated to $\mathrm{T}=0 \mathrm{~K}$, as listed in Table 2 .

The critical current $\mathrm{J}_{\mathrm{c}}^{\mathrm{g}}$, originated macroscopically from the granular structure of the samples (taking into account both the grains and intergrain material) can be calculated from these loops on the basis of Bean's model ${ }^{12}$. This was originally elaborated to study the magnetization of hard superconductors, in which the interstices of a hard superconducting filamentary mesh are filled with a soft superconducting material of a critical magnetic field $\mathrm{H}_{c}$. Shielding of $\mathrm{H}>\mathrm{H}_{\mathrm{c}}$ is performed

TABLE 2

Critical magnetic fields extrapolated to zero temperature

\begin{tabular}{llll}
\hline Samples & $\mathrm{H}_{\mathrm{cl}}(0)(\mathrm{mT})$ & $\mathrm{H}_{\mathrm{c}}(0)(\mathrm{mT})$ & $\mathrm{H}_{\mathrm{c} 2}(0)(\mathrm{T})$ \\
\hline $\mathrm{A}$ & 23.2 & 650 & 32 \\
B & 25.5 & 750 & 34 \\
C & 23.8 & 750 & 37 \\
\hline
\end{tabular}


by a current in the mesh up to a critical current $J_{c}$ to a depth of $\lambda_{B}=10(\mathrm{H}-$ $\left.\mathrm{H}_{\mathrm{c}}\right) / 4 \pi \mathrm{J}_{\mathrm{c}}$ necessary to reduce the internal magnetic field to $\mathrm{H}_{\mathrm{c}}$. Using quasi-cylindrical samples of radius $R$, the magnetization $M$ is given by

$$
\begin{aligned}
& M=-\frac{1}{4 \pi} H, \quad \text { if } \quad 0 \leq \mathrm{H} \leq \mathrm{H}_{\mathrm{c}} \\
& \begin{aligned}
\mathrm{M}=-\frac{1}{4 \pi}\left(-\mathrm{H}+\frac{\mathrm{H}^{2}-\mathrm{H}_{\mathrm{c}}^{2}}{\mathrm{H}^{*}}\right. \\
\left.\quad+\frac{3 \mathrm{H} \mathrm{H}_{\mathrm{c}}^{2}-2 \mathrm{H}_{\mathrm{c}}^{3}-\mathrm{H}}{3 \mathrm{H}^{* 2}}\right), \quad \text { if } \quad \mathrm{H}_{\mathrm{c}} \leq \mathrm{H} \leq \mathrm{H}^{*}+\mathrm{H}_{\mathrm{c}}
\end{aligned}
\end{aligned}
$$

and

$\mathrm{M}=-\frac{1}{4 \pi} \frac{\mathrm{H}^{*}}{3}, \quad$ if $\quad \mathrm{H} \geq \mathrm{H}^{*}+\mathrm{H}_{\mathrm{c}}$

where $\mathrm{H}^{*}=0.4 \mathrm{~J}_{\mathrm{c}} \mathrm{R}$ is the excess over the bulk critical field necessary to induce $\mathrm{J}_{\mathrm{c}}$ to flow through the total sample, i.e., when $\lambda_{\mathrm{B}}=\mathrm{R}$. The application of Bean's model requires that the grains are treated as the filamentary mesh and the intergrain material as the interstices ${ }^{13}$. The results obtained in this way for $\mathrm{J}_{\mathrm{c}}^{\mathrm{g}}$ enable the effect of using different starting materials in the preparation procedure to be evaluated (see Table 3).

If we take the hysteresis curves at magnetic fields lower than $H_{c 1}$ (Fig. 6), then only the intergrain critical current appears, which is responsible alone for the magnetization. At zero magnetic field the weak coupling network disturbs the application of Bean's model because the screening currents are distributed nonuniformly across the samples. The measuring field must be chosen $(\sim 1-1.5 \mathrm{mT})$ such that uniform distribution of the magnetic fluxes throughout the intergrain regions is proven. The values of this magnetic intergrain critical current $\mathrm{J}_{\mathrm{c}}^{\mathrm{im}}$ are summarized again in Table 3.

The grain-to-grain superconducting current can be estimated on the basis of the Ambegaokar-Baratoff theory ${ }^{14}$, assuming strong electron-phonon coupling and a barrier thinner than the coherence length:

$\mathrm{J}_{\mathrm{c}}^{\mathrm{i}}=\frac{1}{\mathrm{R}_{\mathrm{n}}} \Delta_{1}(\mathrm{~T}) \mathrm{F}\left(\left[1-\frac{\Delta_{1}^{2}(\mathrm{~T})}{\Delta_{2}^{2}(\mathrm{~T})}\right]^{1 / 2}\right)$

TABLE 3

Different kinds of critical currents characterizing the granular character of samples at $\mathrm{T}=77 \mathrm{~K}$

\begin{tabular}{lllll}
\hline Samples & $\mathrm{J}_{\mathrm{c}}^{\mathrm{im}}\left(\mathrm{A} / \mathrm{cm}^{2}\right)$ & $\mathrm{J}_{\mathrm{c}}^{\mathrm{i}}\left(\mathrm{A} / \mathrm{cm}^{2}\right)$ & $\mathrm{J}_{\mathrm{c}}^{\mathrm{g}}\left(\mathrm{A} / \mathrm{cm}^{2}\right)$ & $\mathrm{J}_{\mathrm{c}}^{\mathrm{t}}\left(\mathrm{A} / \mathrm{cm}^{2}\right)$ \\
\hline $\mathrm{A}$ & 10 & 25 & 32 & 76 \\
B & 20 & 29 & 47 & 93 \\
C & 23 & 36 & 50 & 98 \\
\hline
\end{tabular}




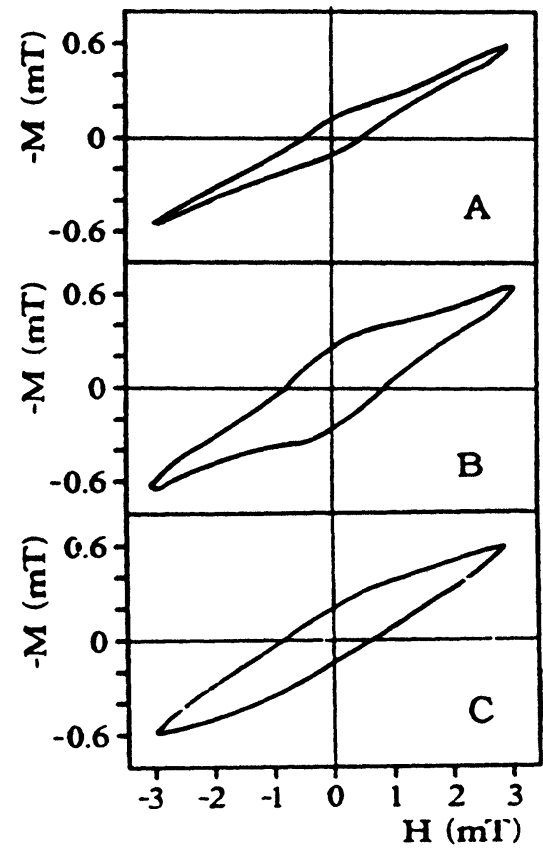

FIGURE 6 Low field magnetization hysteresis at $4.2 \mathrm{~K}$

where the analytical form of $\mathrm{F}$ can be calculated as

$F\left(\Delta(T), \Delta_{2}(T)=\frac{1}{2} \pi \sqrt{\frac{\Delta_{2}(T)}{\Delta_{1}(T)}}\right.$

and $\mathrm{J}_{\mathrm{c}}^{\mathrm{i}}$ corresponds to the intergrain critical current without an external magnetic field, $R_{n}$ is the normal resistance, $\Delta_{1}$ and $\Delta_{2}$ are the smaller and the larger energy gaps. Since $F=\frac{1}{2} \pi$ for equivalent gaps, then $J_{c}^{i}$ represents an upper limit for the maximum superconducting current flowing due to the applied voltage $\mathrm{V}=\frac{1}{2 \mathrm{e}} \pi \Delta$. It has the values listed in Table 3 for comparison of different kinds of samples.

Finally, the varying values of the directly measured transport critical current $\mathrm{J}_{\mathrm{c}}^{\mathrm{t}}$ can also represent the effect of different starting conditions. A similar situation can be found referring to the thermodynamic critical field $\mathrm{Hc}$ and also the upper critical magnetic field $\mathrm{H}_{\mathrm{c} 2}$, as is demonstrated in Table 2 .

As far as the microscopic parameters are concerned, they can be calculated from the macroscopic data using theoretical formulae ${ }^{15,16,17,18}$

$$
\begin{aligned}
& \mathrm{H}_{\mathrm{cl}}=\frac{\phi_{0}}{2 \pi \lambda^{2}} \ln \frac{\lambda}{\xi}, \\
& \mathrm{H}_{\mathrm{c}}=\frac{\phi_{0}}{2 \pi \sqrt{2} \xi \lambda}
\end{aligned}
$$


and

$\mathbf{H}_{\mathrm{c} 2}=\frac{\phi_{0}}{2 \pi \xi^{2}}$

where $\phi_{0}=\mathrm{hc} / 2 \mathrm{e}=2.07 \times 10^{-7}$ Gauss $\mathrm{cm}^{2}$ is the elementary magnetic flux quantum, $\xi$ is the coherence length, and $\lambda$ is the penetration depth. From these quantities the Ginzburg-Landau parameter can also be determined in the form of

$\kappa=\frac{\lambda}{\xi}=\frac{1}{\sqrt{2}} \frac{\mathrm{H}_{\mathrm{c} 2}}{\mathrm{H}_{\mathrm{c}}}$

Table 4 lists these values for the microscopic characteristics of specimens prepared from different batches of starting compounds clearly representing their effect on superconducting properties.

(2). To demonstrate the influence of the annealing procedure, samples were prepared with nominal composition $\mathrm{Tl}_{1} \mathrm{Ca}_{2} \mathrm{Ba}_{2} \mathrm{Cu}_{3} \mathrm{O}_{7.5}$ from $\mathrm{TINO}_{3}$ and $\mathrm{CaO}$ by adding a new barium cuprate $\mathrm{Ba}_{2} \mathrm{Cu}_{3} \mathrm{O}_{5}$.

Specimens A were subjected to the first heat treatment at $205^{\circ} \mathrm{C}$ in air for 2.5 $\mathrm{h}$, then were cooled to room temperature at rate of $100^{\circ} \mathrm{C} / \mathrm{h}$. This resulted in a black, powdery material that was annealed at $940^{\circ} \mathrm{C}$ for $10 \mathrm{~min}$ and cooled at a rate of $50^{\circ} \mathrm{C} / \mathrm{h}$ yielding a black, crumbly product. After grinding and mixing, blocks of dimension $2 \times 0.5 \times 0.25 \mathrm{~cm}$ were pressed by $5 \mathrm{MPa}$, sintered at $870^{\circ} \mathrm{C}$ in air for $15 \mathrm{~min}$ and cooled to room temperature at a rate of $400^{\circ} \mathrm{C} / \mathrm{h}$.

The ground and mixed starting materials of samples $\mathrm{B}$ were first heated at $350^{\circ} \mathrm{C}$ in air for $10 \mathrm{~h}$, followed by cooling at a rate of $100^{\circ} \mathrm{C} / \mathrm{h}$, resulting in a brown powdery product. This was annealed at $940^{\circ} \mathrm{C}$ in air for $10 \mathrm{~min}$ and cooled to room temperature at $50^{\circ} \mathrm{C} / \mathrm{h}$, providing a brown, crumbly material. Blocks of it were then pressed at $5 \mathrm{MPa}$, sintered at $870^{\circ} \mathrm{C}$ in air for $15 \mathrm{~min}$, followed by a very quick cooling of $1000^{\circ} \mathrm{C} / \mathrm{min}$ to liquid nitrogen temperature.

The heat treatment of specimens $\mathrm{C}$ differed from that of $\mathrm{B}$ only in the last cooling step, which had a medium rate of $300^{\circ} \mathrm{C} / \mathrm{h}$ to room temperature.

The effect of different annealing methods shows itself impressively in the difference in microcrystalline structure demonstrated by SEM micrographs (Fig. 7). Samples A show a mixed composition of two different crystallites assuming the shapes of columns and spheres of rather sharp contours. In some places small glasslike islands can also be observed. Specimens B can be characterized with a more

TABLE 4

Microscopic parameters of the specimens depending on starting compounds

\begin{tabular}{llll}
\hline Samples & $\xi(0)(\AA)$ & $\lambda(0)(\AA)$ & $\kappa(0)$ \\
\hline A & 32 & 1200 & 38 \\
B & 31 & 1150 & 37 \\
C & 30 & 1300 & 43 \\
\hline
\end{tabular}



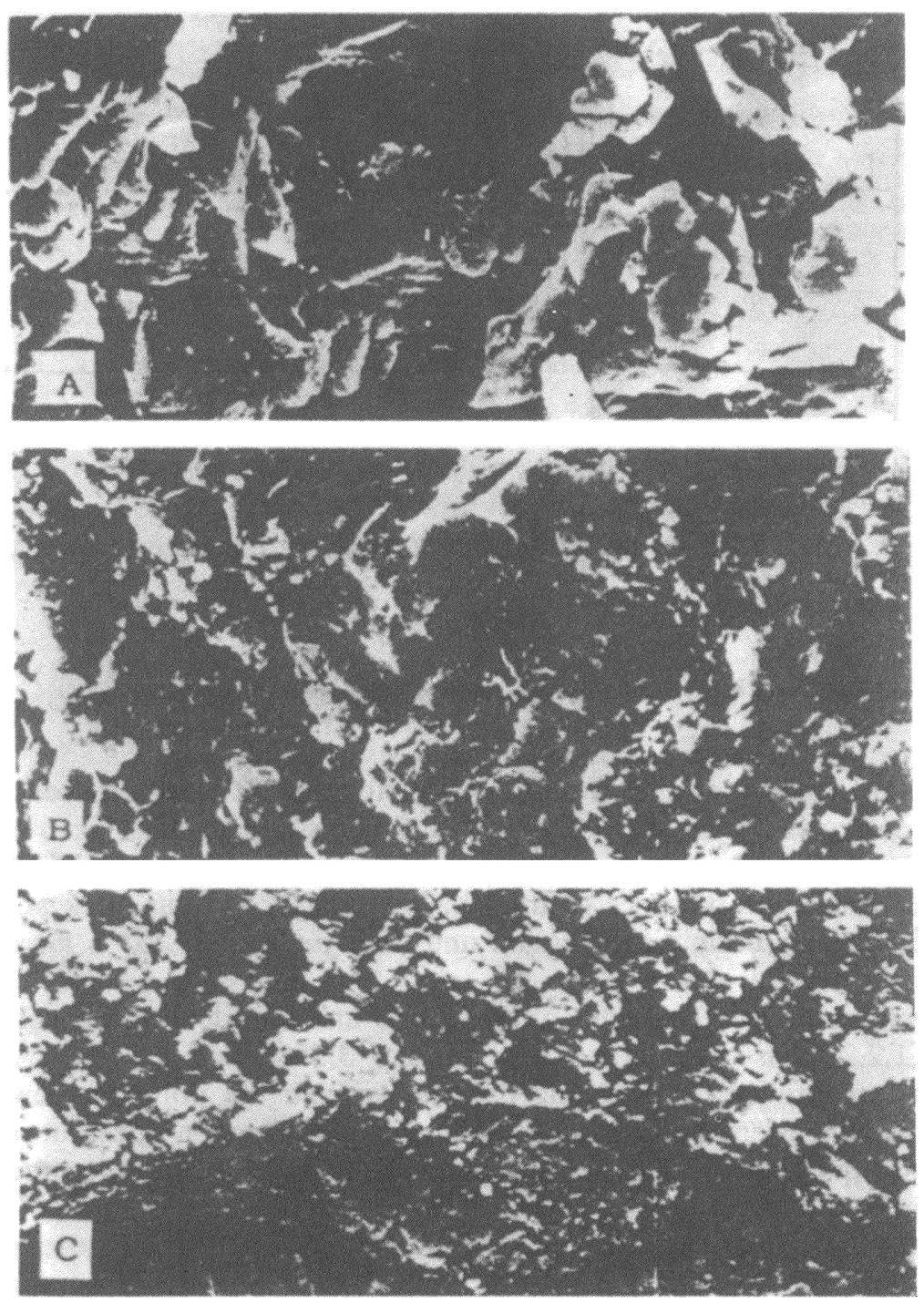

FIGURE 7 SEM photographs of specimens obtained by different heat treatments

homogeneous structure of lower porosity, where the microcrystals are more rounded. They also have some partially crystallized glossy domains frozen in the samples due to the quick final cooling. In contrast with these, specimens $C$ have a well-sintered character without sharp edged microcrystals, but they also contain some well-rounded crystals of various shapes.

Although the analysis of the X-ray investigation of these early-prepared samples ${ }^{19}$ contains certain contradictions, the influence of the different heat treatments is obvious from the diffraction patterns (Fig. 8). Characteristic peaks of the 


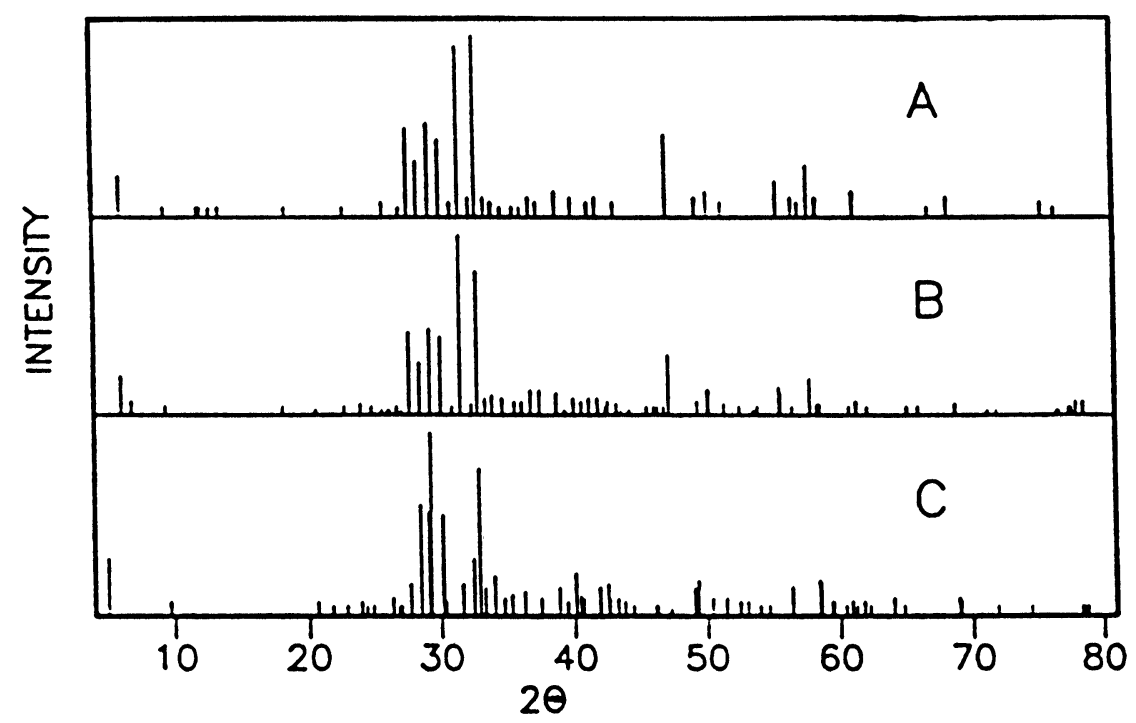

FIGURE 8 X-ray diffractograms of samples annealed variously

$\mathrm{Tl}_{2} \mathrm{CaBa}_{2} \mathrm{Cu}_{2} \mathrm{O}_{8}$ phase appear in all the diffractograms of three different kinds of samples, and peaks of the $\mathrm{Tl}_{2} \mathrm{Ca}_{2} \mathrm{Ba}_{2} \mathrm{Cu}_{3} \mathrm{O}_{10}$ phase, suggested by Hazen et $\mathrm{al}^{5}$, can be also detected in the case of specimens $B$. Intensive peaks at $2 \theta=5.01^{\circ}, 29.08^{\circ}$ and $32.45^{\circ}$ imply the presence of the $(2,2,2,3)$ phase, but our peak at $32.90^{\circ}$ is missing from their basic diffractogram and their peak at $33.18^{\circ}$ is missing from ours.

The well-crystallized character of samples $B$ and the ideal tetragonal unit cell of the $(2,1,2,2)$ phase with lattice constants $\mathrm{a}=3.856 \AA$ and $\mathrm{c}=29.32 \AA$ in these specimens are proven. Interpreting the results from the point of view of heat treatments, a high-temperature superconducting phase can be frozen in samples $B$ due to their quick quenching, but this is probably ruled out by the much slower cooling process of specimens $\mathrm{A}$ and $\mathrm{C}$.

The preparation-induced difference of the microcrystalline structure is also reflected in the superconducting parameters that depend on the microstructure. The first impression inspecting the resistivity curves is the similarity in their form and the difference in their characteristic temperatures. This clearly represents the effect of different heat treatments (Fig. 9). Corresponding to these observations, each sample had the metallic characteristic of decreasing resistivity and the values for $T_{0}$ and $T_{c}$ were obtained as $130 \mathrm{~K}$ and $104 \mathrm{~K}, 125 \mathrm{~K}$ and $107 \mathrm{~K}$ and $109 \mathrm{~K}$ and 93 $\mathrm{K}$ for samples $\mathrm{A}, \mathrm{B}$ and $\mathrm{C}$, respectively.

The real part of the a.c. magnetic susceptibility is also demonstrated in this Figure, which is suitable for the qualification of specimens. In samples A, B and $\mathrm{C}$ the magnetic transition begins at temperatures $116 \mathrm{~K}, 123 \mathrm{~K}$ and $106 \mathrm{~K}$ and finishes at $100 \mathrm{~K}, 77 \mathrm{~K}$ and $72 \mathrm{~K}$, respectively. The extent of the flux exclusion is a maximum in samples $\mathrm{B}$ and only a small difference between the specimens $\mathrm{A}$ and $\mathrm{C}$ can be observed. 


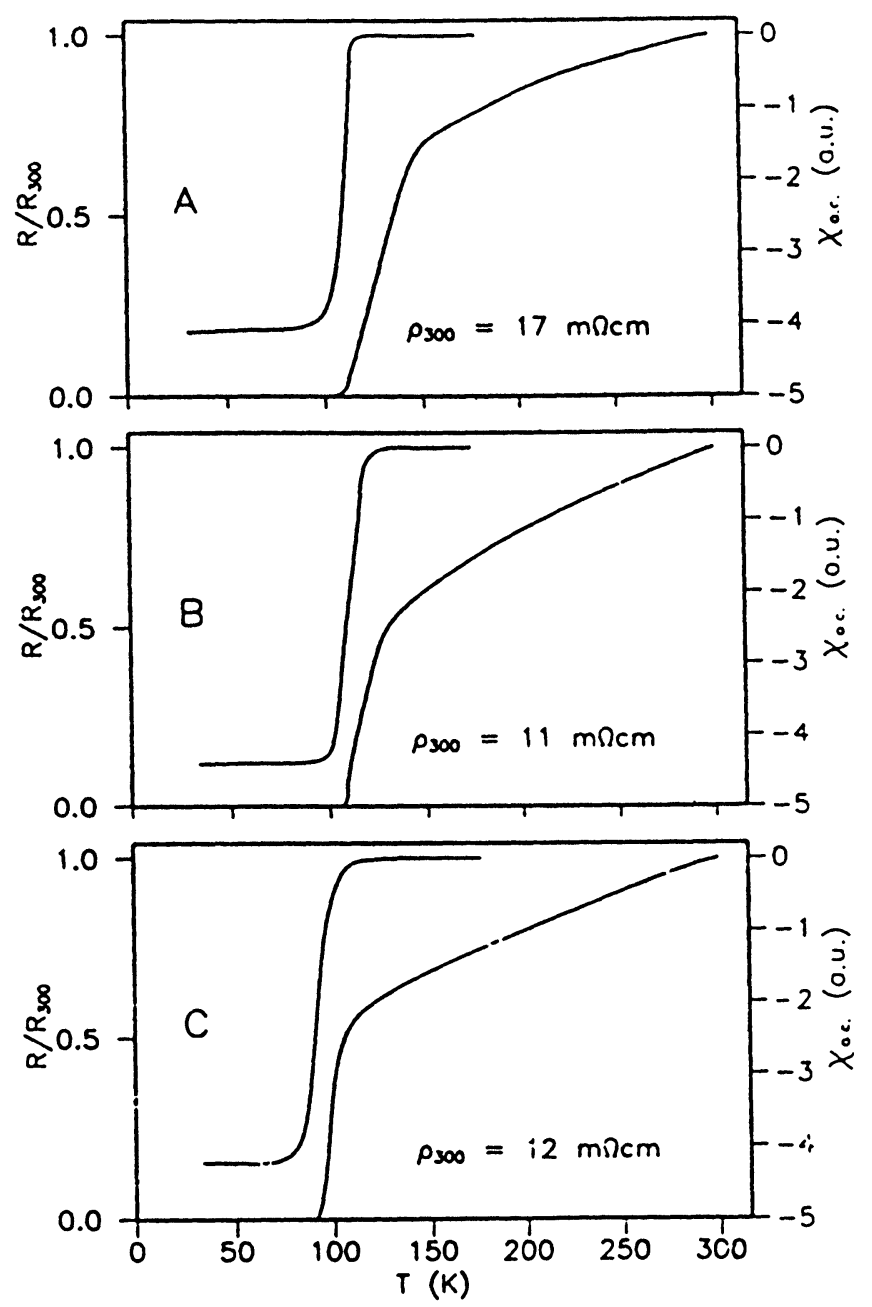

FIGURE 9 Resistivity and a.c. susceptibility of samples having different heat annealing procedure

(3). To illustrate concisely the collective effect of starting compounds, their mixture and heat treatments on the structural and superconducting properties ${ }^{20}$, a few characteristic data are selected for given groups of samples in Tables 5 and 6. The first summarizes the preparation details, while the second one demonstrates some consequences of the different processing routes.

\section{MEASUREMENT OF FINE EFFECTS}

Second order effects may arise due to minor variations of the preparation process. Their investigation provides important supplementary information on the nature of high- $\mathrm{T}_{\mathrm{c}}$ superconductivity. 


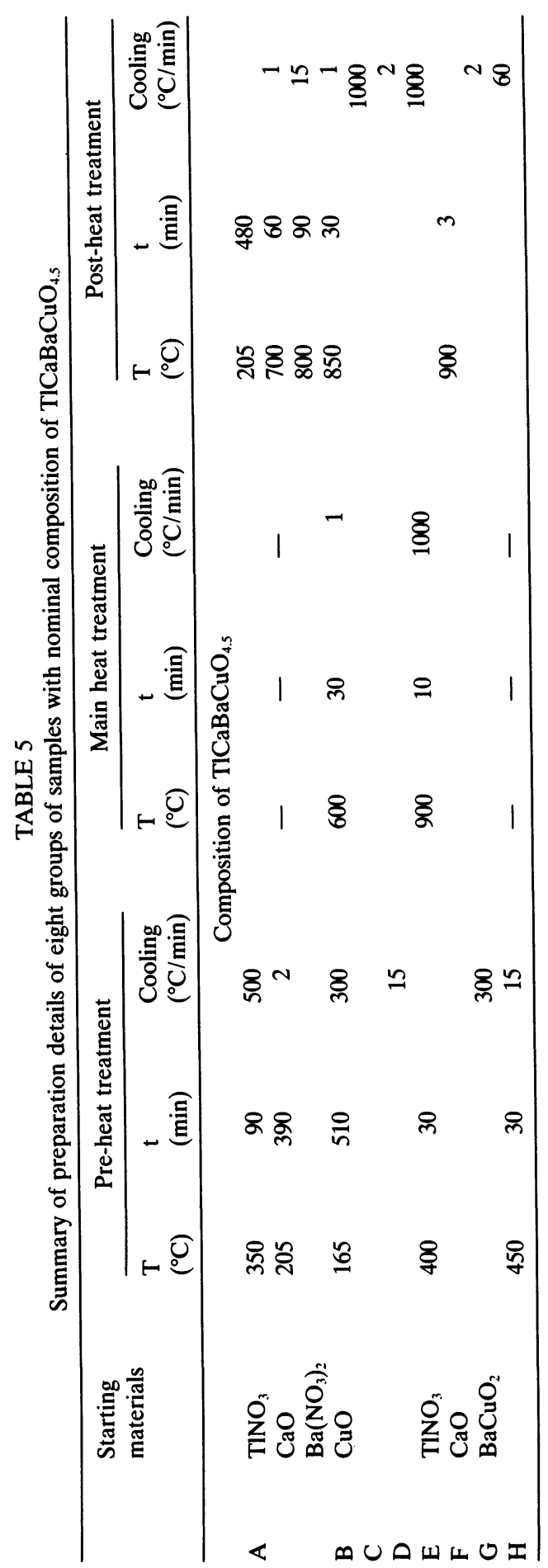




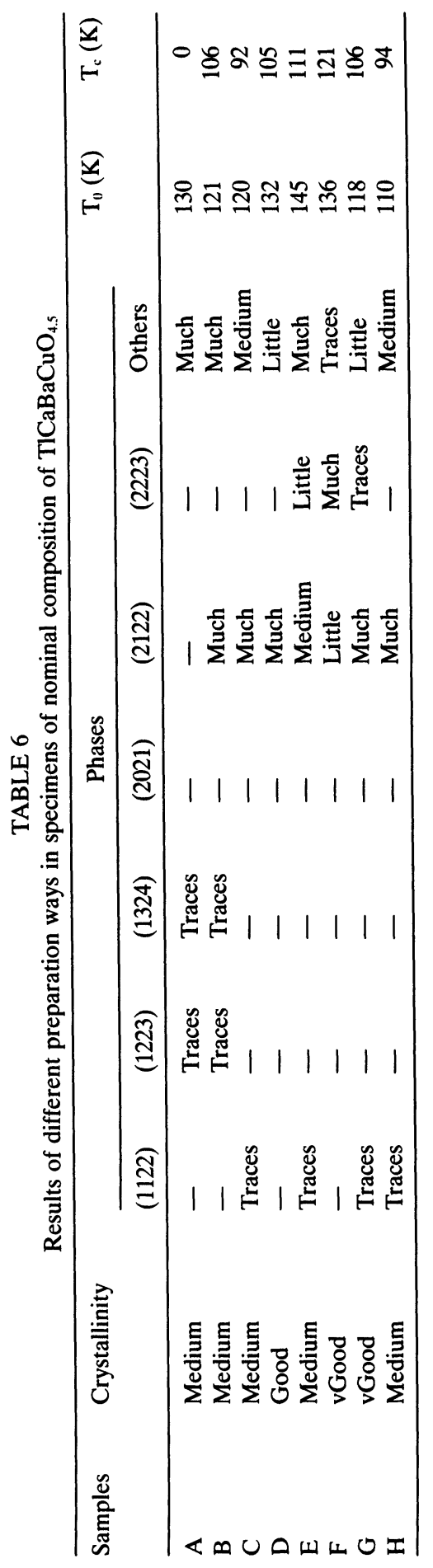




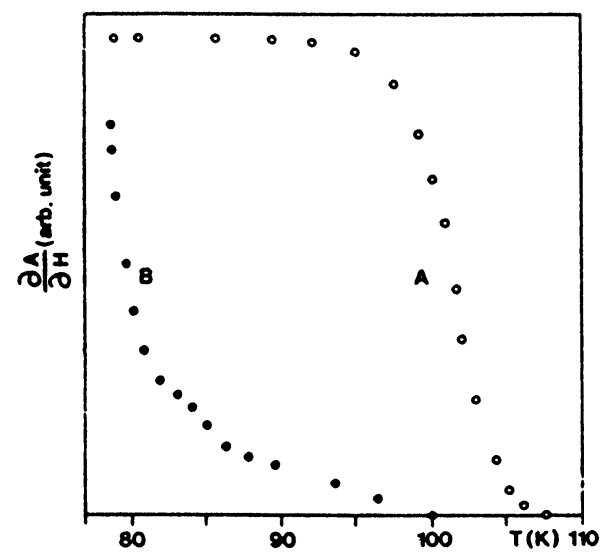

FIGURE 10 Difference in the temperature dependence of the magnetic field derivative of absorption caused by unlike heat treatments

(1). As seen in Fig. 10, different heat treatments can cause different shapes of the zero-field ESR signal (X-band, $9 \mathrm{GHz}$ ) when applied to two samples of the same nominal composition of $\mathrm{Tl}_{1} \mathrm{Ca}_{1} \mathrm{Ba}_{1} \mathrm{Cu}_{1} \mathrm{O}_{4.5}$.

(2). When the preparation process is not fully ideal for the prescribed purpose, or the samples are not in an equilibrium state at the end of it, then a time-dependent behavior can be observed. In this case, the microstructural instability causes a change of the macroscopic parameters of the specimens. In Fig. 11 the saturation character of the onset and critical temperatures is demonstrated. It should be noted that the microscopic background of these phenomena generally cannot be observed by the X-ray method, but NMR investigation is sensitive enough to detect it. The NMR spectra lead to conclusions on the chemical co-ordination of $\mathrm{Tl}$ ions or on the state of $\mathrm{Tl}$ nuclei (which can be metallic or semiconducting). If the repetition of the measurements reveals a temporal change of a given spectrum, microscopic instability is indicated, resulting in time-dependence of certain macroscopic characteristics.

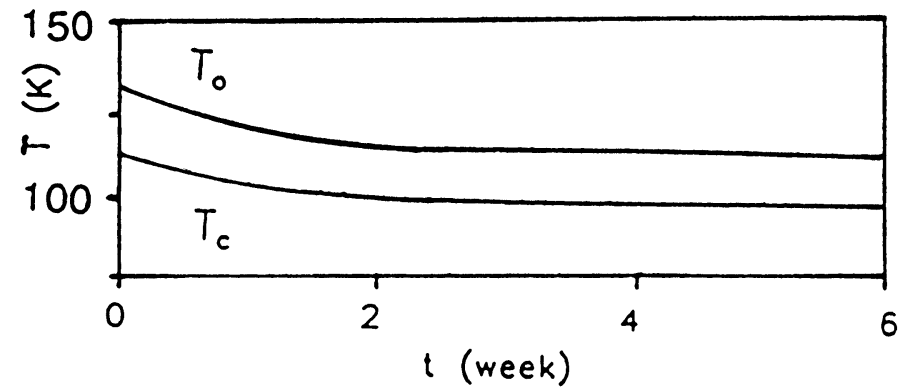

FIGURE 11 Saturation behavior of $T_{0}$ and $T_{c}$ in a sample 


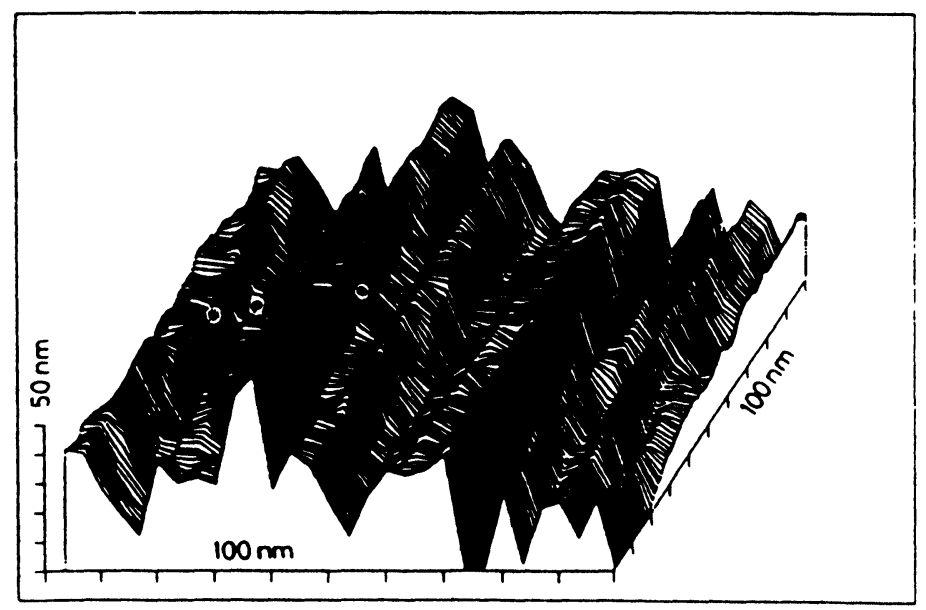

FIGURE 12 Demonstration of a fine surface structure obtained by STM

(3). The resolution of scanning tunneling microscopy (STM) allows us to make very fine mapping of the natural or cleaved surfaces of samples ${ }^{21}$. High-quality scans reveal several traces of dislocation (Fig. 12) inside a square of sizes of 100 $\mathrm{nm} \times 100 \mathrm{~nm}$. If the cell dimensions are observed to vary to some extent, this proves that the samples are not single-phase. The STM scans of the cleaved surfaces show a smoother microstructure than that of the natural surfaces. This could be explained by grains splitting along the layered and orientated structure, causing the highly anisotropic character of the mechanical and transport properties.

(4). In order to obtain detailed information about the effect of the preparation conditions on the stability, structure and site preference, ${ }^{119} \mathrm{Sn}$ and ${ }^{57} \mathrm{Co}$ Mössbauer's spectroscopy may be used ${ }^{22}$.

In Tl-based compounds, the $\mathrm{Sn}$ and $\mathrm{Fe}$ ions replace the regular $\mathrm{Cu}$ sites, but the localization of $\mathrm{Sn}$ atoms in $\mathrm{Tl}$ superconductors is different from that of the other cases $^{23}$, inasmuch as the conditions of preparation govern the substitution process. As the room temperature ${ }^{119} \mathrm{Sn}$ spectrum shows, the doping procedure involves a diffusion of $\mathrm{Sn}^{4+}$ between $\mathrm{Cu}(2)$ sites and rare earth planes and a gradual substitution of $\mathrm{Cu}(2)$. The substitution of $\mathrm{Cu}(1)$ sites ensues only after the saturation of $\mathrm{Cu}(2)$ sites. The lack of ferromagnetic splitting on the ${ }^{57} \mathrm{Fe}$ spectrum taken at liquid nitrogen temperature demonstrates that $\mathrm{Fe}$ ions are built into the perovskite lattice.

Measurements performed over a wide temperature range of 70-295 K demonstrate an anomalous change of the spectra, which is the most striking in the vicinity of $\mathrm{T}_{\mathrm{c}}$ (see Fig. 13), where the total area of the spectra increases. A structural change in the samples is probably responsible for this phenomenon, which can be related to the change of the phonon mode.

(5). Nuclear irradiation leads to a remarkable change in the superconducting properties of high- $T_{c}$ compounds. The defects created by neutrons are mainly vacancies and intersticials of oxygen atoms in $\mathrm{Cu}-\mathrm{O}$ layers and chains. This is 

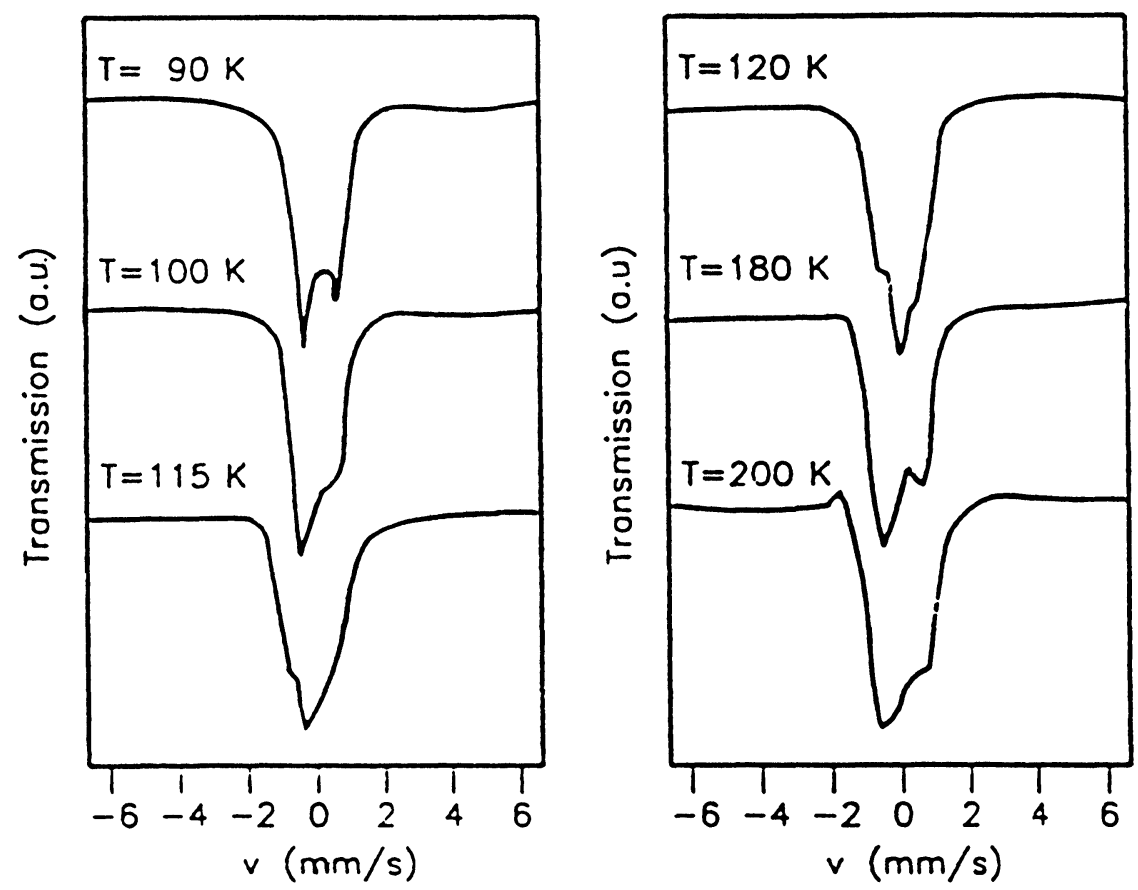

FIGURE 13 Significant change of ${ }^{57} \mathrm{Fe}$ spectra in the investigated temperature interval

connected with the modification of the $\mathrm{Cu}-\mathrm{O}$ bond strength and lattice parameters. The local magnetic moments occurring due to the oxygen vacancies are directly responsible for the change of $T_{c}$.

In the unirradiated specimens the number of oxygen vacancies, i.e., intensity of hole doping influences the $\mathrm{Cu}-\mathrm{O}$ bond strength and length, which are in a strong correlation with superconducting properties. In the case of underdoped hole concentration, when the formal oxidation state of $\mathrm{Cu}-\mathrm{O}$ sheets is $\left(\mathrm{CuO}_{2}\right)^{2-}$, the material is semiconducting and has a long-range antiferromagnetic order of $\mathrm{Cu}$ atoms. When the sheets are oxidized to a mixed valence state $\left(\mathrm{CuO}_{2}\right)^{\mathrm{n}-}$, where $1<\mathrm{n}<2$, the compound becomes superconducting. When the oxidation increases further toward an overdoped $\left(\mathrm{CuO}_{2}\right)^{1-}$ state, the superconductivity vanishes and the material goes over into the normal metallic state. This means that $\mathrm{T}_{\mathrm{c}}$ has a maximum value at an optimum oxygen hole concentration, increases in an underdoped hole region, and decreases in an overdoped interval with the increasing hole concentration.

Based on these facts, low-dose neutron irradiation can result in either an improvement or a degradation of superconducting parameters. In our case ${ }^{25}$, a maximum increase of $\mathrm{T}_{\mathrm{c}}$ of about $2-3 \mathrm{~K}$ was found and the best enhancement of the superconducting volume fraction was $23 \%$.

(6). The preparation details can also bring about peculiar effects of which hyper-diamagnetism is one example. Using a previously tested heat treatment process, variations between specimens was in correlation with differences between the groups of starting compounds ${ }^{26}$. 
The annealing procedure consists of three stages: heating at $450^{\circ} \mathrm{C}$ (followed by a slow cooling), a second heating at $900^{\circ} \mathrm{C}$ (followed by a very quick cooling to liquid nitrogen) and a sintering at $900^{\circ} \mathrm{C}$ (followed by a low-rate cooling). This was applied to different groups of starting materials, as $\mathrm{TlNO}_{3}, \mathrm{CaO}, \mathrm{Ba}\left(\mathrm{NO}_{3}\right)_{2}$ and $\mathrm{CuO}$ for samples $\mathrm{A}, \mathrm{TINO}_{3}, \mathrm{CaO}, \mathrm{BaO}$ and $\mathrm{CuO}$ for specimens $\mathrm{B}$, and $\mathrm{TINO}_{3}$, $\mathrm{CaO}$ and $\mathrm{BaCuO}_{2}$ for samples $\mathrm{C}$.

$\mathrm{X}$-ray investigation of samples $\mathrm{A}$ reveals the least crystallized structure, of $\mathrm{B}$ a medium structure while samples $\mathrm{C}$ demonstrate the best crystallinity. Besides the principal $(2,1,2,2)$ phase, samples $\mathrm{A}$ contain non-superconducting $\mathrm{Ba}_{2} \mathrm{Cu}_{3} \mathrm{O}_{5}$ (in 5$10 \%)$ and superconducting $(2,0,2,1)$ in traces, specimens $B$ have strongly oriented $(2,2,2,3)$ and $(2,0,2,1)$ phases in about $10-15 \%$, while in samples $C$ some nonreacted $\mathrm{BaCuO}_{2}$ in $5-10 \%$ and $(2,2,2,3)$ in low quantity can be found.

The distortion of the tetragonal lattice of $(2,1,2,2)$ was small in samples $A$ and $\mathrm{C}$, but significant in specimens $\mathrm{B}$. The reason for this deviation may be sought in the interaction of different crystalline phases, i.e., intergrowths, in the formation of superstructures and in the mutual substitution of $\mathrm{Ca}$ and $\mathrm{Ba}$ ions.

The samples have similar behavior from the point of view of the electrical properties and rather sharp superconducting transitions, except specimens $B$. The characteristic onset and critical temperatures are $113 \mathrm{~K}$ and $104 \mathrm{~K}, 116 \mathrm{~K}$ and 102 $\mathrm{K}$ and $115 \mathrm{~K}$ and $105 \mathrm{~K}$ for samples $\mathrm{A}, \mathrm{B}$ and $\mathrm{C}$, respectively.

The quasi-single-phase character of samples $A$ and $C$ is well reflected in the shape of the temperature dependence of d.c. susceptibility $\chi_{\text {d.c. }}$ and the disappearance of the diamagnetic signal at $T_{c}$. Specimens $B$, however, have a quite different feature. First of all, their $\chi_{\text {d.c. }}-T_{c}$ curve demonstrates a multi-phase character by its kink-like shape appearing at about $95 \mathrm{~K}$ (see Fig. 14). On the other hand, the diamagnetic signal can be observed at the temperatures above $T_{c}$ up to $132 \mathrm{~K}$. Although the signal magnitude is less by four orders in the high-temperature

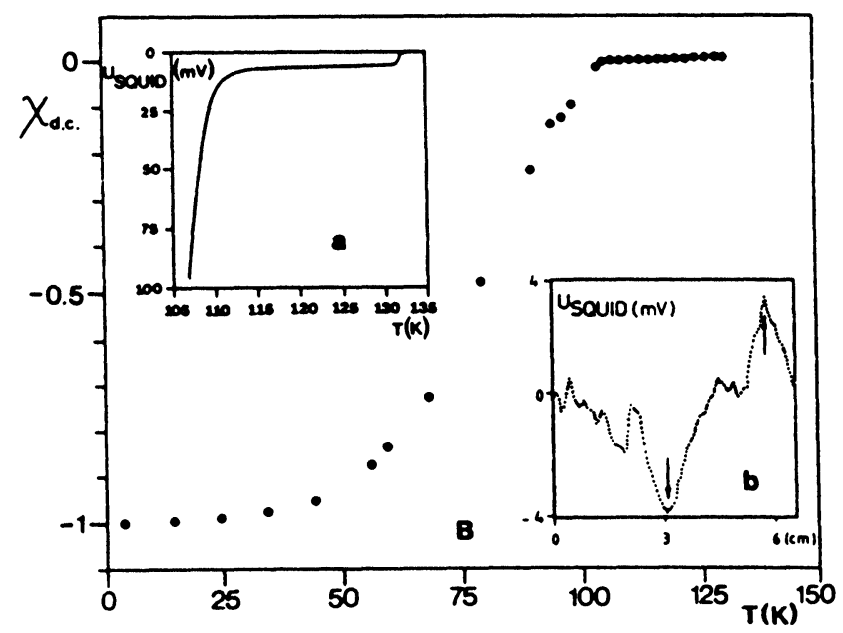

FIGURE 14 Existence of a diamagnetic signal above $T_{c}$ 
interval than in the liquid helium range (insert a), it is well measurable and much higher than the noise level (insert $b$ ). Based on these data, the high-temperature diamagnetic or superconducting content constitutes only a $1.2 \times 10^{-4}$ part of that existing at helium temperatures. If this small amount of material distributes into discrete islands, it cannot be detected by electrical methods.

During repeated measurements, a temporal change was observed at which the hyper-diamagnetic signal ceased above $113 \mathrm{~K}$ within two weeks of the sample preparation.

The results obtained were supported by transmission electron microscopy, using both of SAED and HRTEM methods. As the main results of this investigation show, in some grains of specimens B the $(2,1,2,2)$ phase is predominant having a disordered interstratification of the $(2,2,2,3)$, while in other grains the $(2,2,2,3)$ host phase is interstratificated by the $(2,1,2,2)$ in the form of disordered distribution (Fig. 15). Finally, the existence of hyper-diamagnetism can be attributed to this observed superstructure.

The time-dependent nature was also detected by this procedure, which hinted at a microstructural change and its decay in half a year after the preparation of samples B.

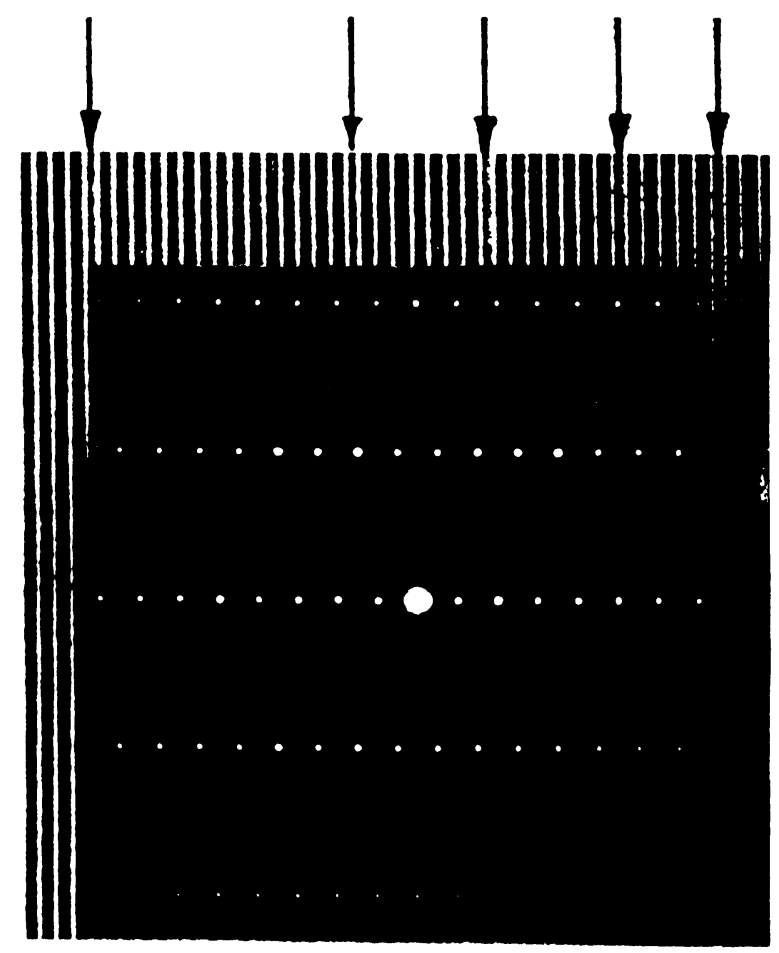

FIGURE 15 A HRTEM micrograph and a SAED pattern demonstrating the interstratification of phases $(2,1,2,2)$ and $(2,2,2,3)$ 


\section{CONCLUSIONS}

Summarizing the knowledge gained in the course of the research program, some conclusions can be drawn:

1. The experiments show that there is a correlation between the chemical quality, the mixing ratio, and heat annealing process as input conditions, microstructure, crystallinity, and type and number of phases at an intermediate stage and the superconducting parameters as output. The macroscopic parameters and their possible variations with time are influenced, however, by fine interactions reflecting the effect of individual ions within ionic groups.

2. The stability of the structure of samples is determined by the Van der Waalstype forces causing intergrowths, by the presence of $\mathrm{CaO}$ helping formation of quasi-crystals, and by low melting point starting compounds, e.g., $\mathrm{Ba}\left(\mathrm{NO}_{3}\right)_{2}$, resulting in glassy domains and producing a more compacted structure and an improvement of the intergrain weak links.

3. Only the specific mixture of the starting materials can be reacted to create a predictable single-phase material following an appropriate annealing process. In addition to the known superconducting phases, other phases and non-stoichiometric modifications can be formed. The effect of purified oxygen is to perfect the superconducting properties.

4. The superconducting critical parameters are dependent on the heat treatment process even inside the same nominal composition.

5. The type and sizes of the grains comprising the samples are determined jointly by the starting compounds and heat treatments, employed.

\section{REFERENCES}

1. Z.Z. Sheng and A.M. Hermann, Nature 332, 55 (1988).

2. Z.Z. Sheng and A. M. Hermann, Nature 332, 138 (1988).

3. I. Kirschner, I. Halasz, G. Sükosd, T. Porjesz, J. Kürti, Gy. Kovács, L. Korecz, T. Kàrmán, N.S. Rozlosnik, G. Zsolt and T. Träger, Phys. Lett. A130, 39 (1988).

4. A. Sulpice, B. Giordanengo, R. Tournier, M. Hervien, A. Maignan, C. Martin, C. Michel and J. Provost, Physice C153, 243 (1988).

5. R.M. Hazen, L.Q. Finger, R.J. Angel, C.T. Previtt, N.L. Ross, A.M. Hermann, C.G. Hadidiacos, P.J. Heaney, D.R. Veblen, Z.Z. Sheng and A. El-Ali, Phys. Rev. Lett. 60, 1657 (1988).

6. M.A. Subramanian, J.C. Calabrese, C.C. Torardi, J. Gopalakrishnan, T.R. Askew, R.B. Flippe, K.J. Morrisey, U. Chowdhry and A.E. Sleight, Nature 332, 420 (1988).

7. A.W. Hewat, Europhys. News 19, 73 (1988).

8. R. Beyers, S.S. Parkin, V.J. Lee, A.I. Nazzal, R. Savoy, G. Gorman and T.C. Huang, Appl. Phys. Lett. 53, 432 (1988).

9. I. Kirschner, in the book Studies of High Temperature Superconductors, vol. 9, ed. A. Narlikar, Nova Sci. Publ., New York, 1991.

10. I. Kirschner, S. Leppävuori, R. Laiho, A.D. Caplin, I. Halász, T. Porjesz, A. Uusimäki, G. Zsolt, E. Lähderanta, T. Kàrmán, J. Laverty and Gy. Kovács, Gryogenics 31, 33 (1991).

11. S.E. Male, J. Chilton, A.D. Caplin, C.N. Guy and S.B. Newcomb, Supercond. Sci. Techn. 2, 9 (1989).

12. C.P. Bean, Phys. Rev. Lett. 8, 260 (1962).

13. I. Kirschner, S. Leppävuori, R. Laiho, A.D. Caplin, T. Kàrmán, E. Lähderanta, G. Zsolt, A. Uusimäki, J. Laverty, T. Porjesz, I. Halász, J. Levoska and Gy. Kovács, Zeit. Phys. B78, 381 (1990). 
14. V. Ambegaokar and A. Baratoff, Phys. Rev. Lett. 10, 486 (1963).

15. J. Bardeen, Z.N. Cooper and J.R. Schrieffer, Phys. Rev. 108, 1175 (1957).

16. V.L. Ginzburg and L.D. Landau, Journ. Exp. Teor. Fiz. 20, $1064\left(1^{\mathrm{o}} \mathrm{0}\right)$ ).

17. A.A. Abrikososv, Journ. Exp. Teor. Fiz. 32, 1442 (1957).

18. L.P. Gorkov, Journ. Exp. Teor. Fiz. 36, 1918 (1959); 37, 833 (1959).

19. I. Kirschner, I. Halász, T. Träger, J. Tóth, Gy. Kovács, T. Porjesz, G. Zsolt and T. Kármán. Zeit. Phys. B73, 293 (1988).

20. Gy. Kovács, I. Kirschner, I. Halász, R. Laiho, T. Porjesz, K. Tompa, T. Träger, T. Kármán and G. Zsolt, Journ. Less-Comm. Met. 150, 229 (1989).

21. R. Laiho, M. Aarnio, L. Heikkilä, H. Snellmann, I. Kirschner and I. Halász, Journ. Microscopy 152, 407 (1988).

22. E. Kuzmann, Z. Homonnay, A. Vértes, M. Gál, K. Torhos, B. Csákvári, K.G. Sólymos, G. Horváth, J. Bánkuti, I. Kirschner and L. Korecz, Phys. Rev. B39, 328 (1989).

23. E. Kuzmann, Z. Homonnay, A. Vértes, I. Halász, J. Bánkuti and I. Kirschner, Journ. Radioanal. Nucl. Chem. Lett. 135, 373 (1989).

24. E. Kuzmann, Z. Homonnay, A. Vértes, L. Bottyán, I. Kirschner, I. Halász, J. Bánkuti, K. Korecz and J. Dengler, Hyperfine Interactions 55, 1331 (1990).

25. A.C. Bódi, J. Csikai, R. Pepelnik, I. Halász, I. Kirschner, Gy. Kovács, T. Porjesz and T. Träger, Physica C165, 83 (1990).

26. T. Kármán, E. Lähderanta, S. Leppävuori, I. Halász, I. Dódony, G. Zsolt, T. Porjesz, R. Laiho, A. Uusimäki, I. Kirschner and Gy. Kovács, Zeit. Phys. B78, 169 (1990). 

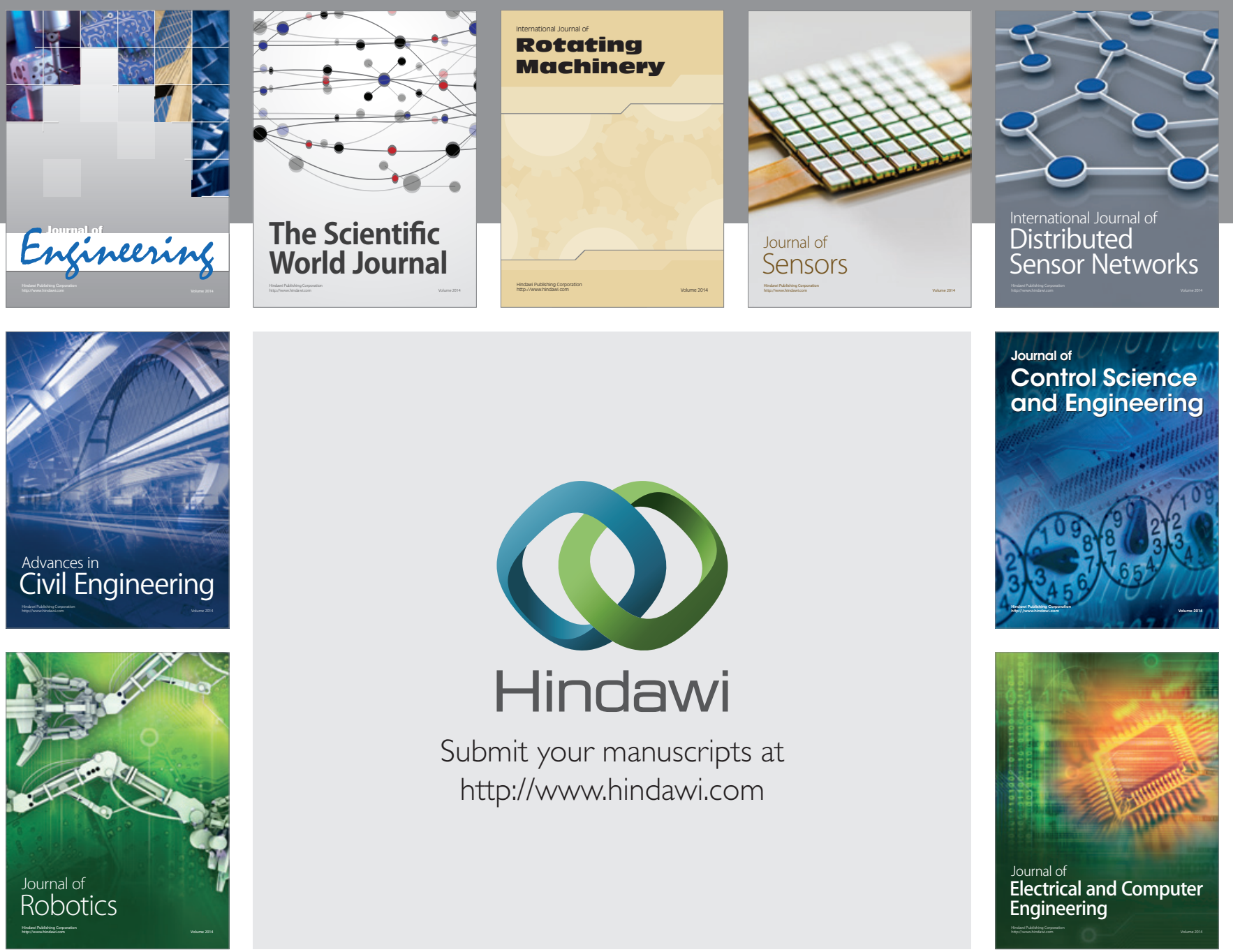

Submit your manuscripts at

http://www.hindawi.com
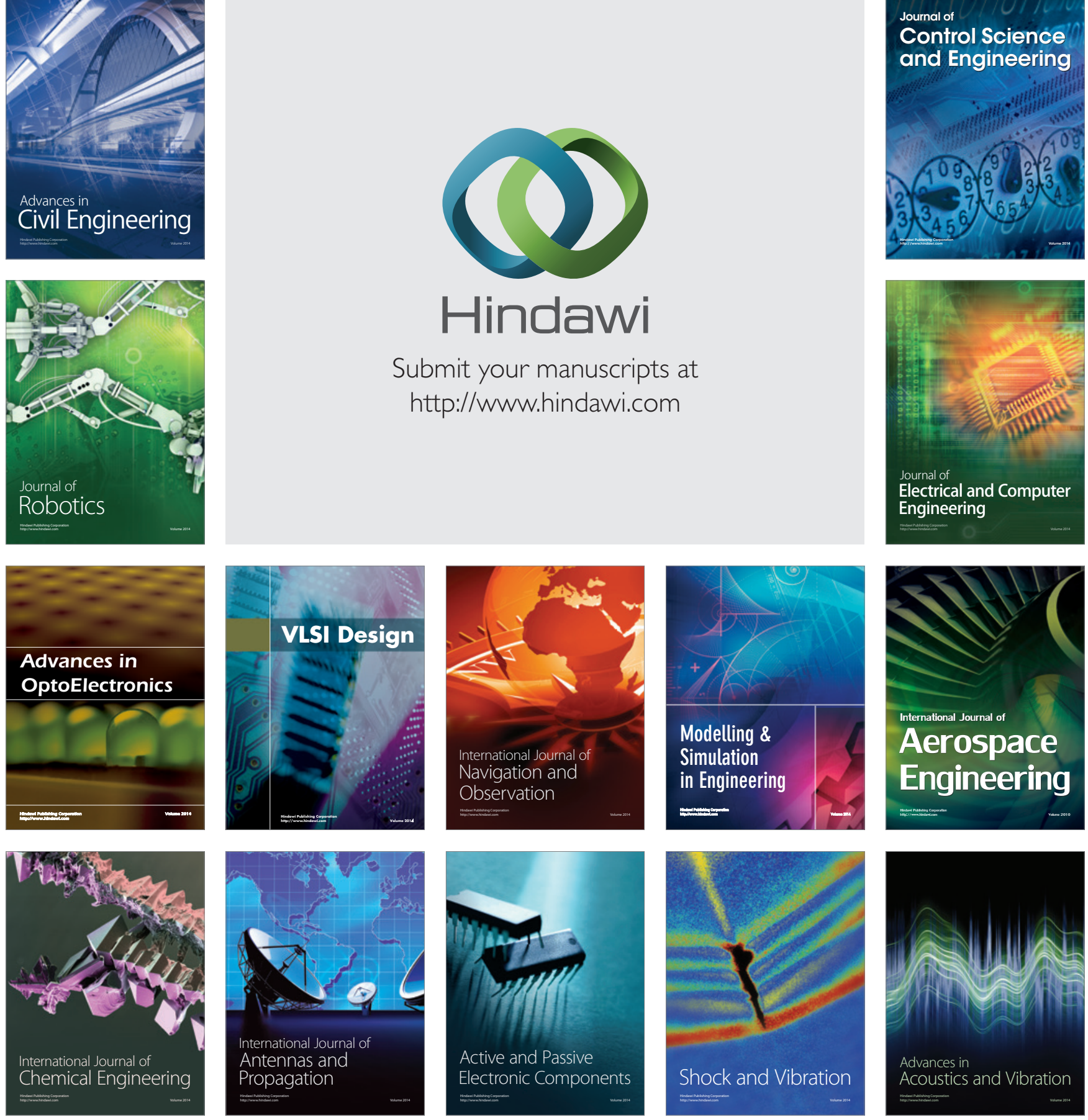